\title{
Radiation Capture and Use as Affected by Morphologically Contrasting Maize/Pea in Sole and Intercropping
}

\author{
R. A. L. Kanton ${ }^{1 *}$ and M. D. Dennett ${ }^{2}$ \\ ${ }^{1}$ Savanna Agricultural Research Institute, Manga Agricultural Research Station, $\quad$ P. O. Box 46, \\ Bawku, Upper East Region, Ghana \\ ${ }^{2}$ Department of Agricultural Botany, School of Plant Sciences, The University of Reading, P. O. Box 221, \\ RG6 6AS Reading, UK \\ *Corresponding author
}

\begin{abstract}
Field experiments were conducted at the Field Unit of the School of Plant Sciences in Reading, UK, during the 2000 and 2001 growing seasons to compare the radiation capture and use efficiency of morphologically and physiologically contrasting maize/pea intercrops with sole crops. The maize cultivars comprised Nancis with erect and Sophy with floppy leaves whilst the peas consisted of Maro, a conventional leaved, and Princess, a semi-leafless cultivar. Radiation capture by the sole and intercrops was measured using a Sunflek Ceptometer (Delta T Devices), with a sensor length of $80 \mathrm{~cm}$. Measurements were taken at four equidistant positions in each plot, $1 \mathrm{~m}$ away from the edges of the plot. Before the maize grew above the peas, measurements were taken at the top of the canopy and below. When the canopies were distinct, three measurements were taken, above the canopy, above peas and below the canopy from 9.30 a.m. to 1.00 p.m. at weekly intervals. In both seasons the intercrops and sole pea crops intercepted more radiation compared to the sole maize crops. Towards the end of the season the intercrops and sole maize had similar interception. Intercropping both maize cultivars in 2000 with the conventional pea had the greatest interception in 2001. Radiation use efficiency (RUE) was measured by taking the respective changes in above ground dry weight and dividing by the respective changes in cumulative absorbed photosynthetic active radiation (PAR). The RUE were highest at mid-season for both intercrops and sole crops in both seasons. Comparisons were also made using cumulative radiation use efficiencies (CRUE), representing the RUE from emergence to any time. Sole pea had the lowest CRUE in both seasons. The sole maize in 2000 had highest CRUE. However, in 2001 intercrops had similar CRUE to sole maize, suggesting an increase in RUE of peas in intercrops. Nancis had consistently higher CRUE in both seasons compared to Sophy. The results emphasize that radiation capture and use efficiency in sole and intercrops are greatly affected by morphological characteristics of the component crops. In choosing cropping partners for intercropping special attention should be given to selecting cereal crops with erect leaves as against those with droopy leaves. The under-storey legume crop should also have erect or semi erect leaves so as to capture radiation filtering through the cereal canopy in order to maximize the capture and use of photosynthetically active radiation for increased and stable yields.
\end{abstract}

\section{Introduction}

Most intercrop studies report yield advantages of intercropping compared to sole cropping but the scientific basis of these yield advantages is often not considered (Matthews, 2000). In cases where possible mechanisms are mentioned they are often mere speculations with no empirical data to substantiate them (Matthews, 2000). Differences in the competitive abilities of component crops in an intercrop affect the performance of the entire system (Azam-Ali \& Squire, 2002). Solar radiation must be intercepted and utilized instantaneously as it cannot be stored for later use. Keating \& Carberry (1993) reported that inter-cropping could increase the interception of solar radiation and maintain higher radiation use efficiency. Willey (1990) concluded that the radiation capture required to produce actual intercropping yields at sole crop efficiencies was about $30 \%$ more than the actual radiation, implying an increase in the efficiency of radiation use by intercrops.

The shading effect of a vertically dominant species in an intercrop can be partly reduced if the taller species has erectophile leaves above an understorey species with planophile leaves (Sinoquet \& Caldwell, 1995). Several workers have reported higher rate of photosynthesis, better light penetration, and use for erect-leaved than drooping-leaved maize and other cereals (Angus et al., 1972; Sinclair, 1972; Pandey et al., 1976; Vidovic, 1979; Wang et al., 1996). Cudney et al. (1991), in a study on the effect of wild oat infestation on light interception and growth of wheat, concluded that differences in height were the most

West African Journal of Applied Ecology - Volume 13 
important factor affecting light penetration. In light competition not only foliage height but also foliage inclination angles should be important (Caldwell, 1987).

The objective of the study was to compare the absorption and use of radiation by morphologically contrasting cultivars of maize and peas in sole crops and intercrops. The following hypotheses were tested: (a) maize has a higher radiation use efficiency (RUE) than pea, (b) morphological differences should alter the amount of absorbed radiation and RUE in sole crops, (c) intercrops absorb more radiation and have higher RUE than the sole crops, and (d) the radiation absorbed and the RUE of the intercrops depend upon the morphology of the component crops.

\section{Experimental site}

\section{Materials and methods}

Field experiments were conducted at the Field Unit of the School of Plant Sciences, The University of Reading, Shinfield $\left(51^{\circ} 25^{\prime} \mathrm{N}, 0^{\circ} 56^{\prime} \mathrm{W}, 40 \mathrm{~m}\right.$ a.s.l) in 2000 and 2001. In 2000 the experiment followed fallow, which had for the previous 6 years been cropped with wheat. In 2001 the experiment followed several years of natural pasture. The total experimental area was $94 \mathrm{~m} \times 40 \mathrm{~m}$ in each year. The soil was a sandy clay loam overlying river terrace gravel, belonging to Hurst series (Jarvis, 1968). The top $30 \mathrm{~cm}$ in the first year experiment was sandy whilst that of the second year had more gravel and stones. In both fields the clay content increased gradually with depth.

\section{Experimental materials}

The experimental material comprised of two morphologically contrasting cultivars of maize (Zea mays L.) and of peas (Pisum sativum L.). The maize cultivars were Nancis and Sophy and the peas were Maro and Princess. Nancis has an erect leaf habit below average dry matter yields of very high dry matter content, very early cob maturity, and belongs to maturity class 7 (Anon., 1999a). Sophy has the traditional droopy leaf habit, and high dry matter yields of high dry matter content. Sophy is tall at harvest, but with good standing ability and is from maturity class 10 (Anon., 1999a).

Pea cultivar Maro is a normal-leaved, marrowfat variety (Anon., 1999b). It is late maturing with poor standing ability and ease of combining. Princess is a moderately tall-strawed, semi-leafless, marrowfat variety possessing good standing ability and ease of combining (Anon., 1999b). The semi-leafless pea phenotype maintains a comparable crop growth rate with conventional leaved but with higher standing ability (Pyke \& Hedley, 1985). The lower photosynthetic capacity of the semi-leafless pea is compensated for by its physical characteristics, of being semi-leafless pea, allowing more light to pass through its canopy than the conventional-leaved pea, thereby, maintaining a better light distribution over a larger lamina area than the conventional canopies (Pyke \& Hedley, 1985).

\section{Experimental design}

The field experiments in both years were laid out in a randomized complete block design with three replications. The experimental plots were $7 \mathrm{~m} \times 10 \mathrm{~m}$ with $5 \mathrm{~m}$ between plots. The experimental treatments comprised of all combinations of the maize cultivars, erect leaved and droopy leaved and peas cultivars, normal leaved and semi-leafless and their respective sole crops, giving eight treatments combination. The experimental treatments were randomly assigned in each of the three replicates.

\section{Land preparation, sowing and crop management}

The sites were ploughed in February and cultivated, ring-rolled and leveled in May. Compound fertilizer (15:15:15) was broadcast by hand at the rate of $40 \mathrm{~kg} \mathrm{ha}^{-1}$ of $\mathrm{N}, \mathrm{P}_{2} \mathrm{O}_{5}$ and $\mathrm{K}_{2} \mathrm{O}$ in 2000, but in 2001 no fertilizer was applied. In 2000 peas were drilled using a Wintersteiger Precision Seed Drill on June 6, and maize was hand-sowed on June 7 and 8. In 2001 peas were drilled on May 24 whilst maize was hand-sowed on May 25 and 26. Peas were sown at a density of 71 plants $\mathrm{m}^{-2}$ and maize at a density of 6 plants $\mathrm{m}^{-2}$. In the intercrops, maize rows were spaced at $0.75 \mathrm{~m}$ apart with a within row spacing of 0.30 $\mathrm{m}$. Each maize row was alternated with six rows of pea at $0.12 \mathrm{~m}$ apart with a within row spacing of

West African Journal of Applied Ecology - Volume 13 
about $0.07 \mathrm{~m}$. The same maize and peas densities were adopted for their respective sole crops, thus, giving an additive design. Weeds were controlled by hand weeding at 14 and 28 days after sowing (DAS). Peas matured earlier (85-90 DAS) than maize (120-125 DAS). The mature peas were left in the intercrops whilst the maize matured.

Weather conditions during the experi-mental period in both years

Weather data are presented in Table 1. Rainfall totals were similar but in 2000 there was less rain (114 $\mathrm{mm}$ ) from sowing to $100 \mathrm{DAS}$ compared to $152 \mathrm{~mm}$ in 2001 . Mean daily solar radiation in 2000 was $13.1 \mathrm{MJ} \mathrm{m}$ ${ }^{2}$ compared to $15.9 \mathrm{MJ} \mathrm{m}^{-2}$ in 2001.

TABLE 1

Total rainfall mean minimum and maximum temperatures and solar radiation for decadal periods during the growing season in 2000 and 2001

\begin{tabular}{crrrrrrrr} 
& $\begin{array}{r}\text { Rainfall }(\mathrm{mm}) \\
\left({ }^{\circ} \mathrm{C}\right)\end{array}$ & \multicolumn{2}{c}{$\begin{array}{c}\text { Min. temperature } \\
\left({ }^{\circ} \mathrm{C}\right)\end{array}$} & \multicolumn{2}{c}{$\begin{array}{c}\text { Max. temperature } \\
\left(\mathrm{MJm}^{-2} \mathrm{~d}^{-1}\right)\end{array}$} \\
\multicolumn{1}{c}{ DAS } & 2000 & 2001 & 2000 & 2001 & 2000 & 2001 & 2000 & 2001 \\
& & & & & & & & \\
$0-9$ & 5.6 & 0.3 & 11.2 & 9.5 & 20.0 & 18.1 & 17.4 & 13.1 \\
$10-19$ & 7.7 & 1.4 & 12.0 & 6.2 & 21.1 & 17.3 & 15.7 & 18.3 \\
$20-29$ & 22.8 & 32.1 & 11.9 & 8.5 & 20.0 & 19.8 & 12.5 & 20.0 \\
$30-39$ & 22.7 & 0.4 & 10.9 & 13.1 & 18.2 & 25.0 & 12.0 & 20.0 \\
$40-49$ & 0.0 & 19.3 & 10.4 & 14.2 & 21.0 & 23.0 & 19.4 & 20.1 \\
$50-59$ & 18.1 & 16.6 & 14.0 & 10.1 & 24.8 & 20.1 & 17.0 & 15.5 \\
$60-69$ & 4.2 & 0.0 & 13.6 & 13.0 & 23.6 & 26.8 & 14.0 & 14.1 \\
$70-79$ & 8.0 & 47.1 & 11.5 & 11.4 & 22.6 & 21.9 & 16.3 & 19.3 \\
$80-89$ & 18.0 & 32.9 & 10.2 & 13.9 & 20.1 & 23.1 & 12.7 & 13.3 \\
$90-99$ & 5.5 & 6.0 & 12.5 & 11.7 & 21.4 & 22.6 & 10.1 & 15.1 \\
$100-109$ & 42.2 & 14.5 & 11.4 & 10.4 & 18.1 & 18.7 & 7.8 & 14.4 \\
$110-119$ & 38.4 & 14.0 & 9.5 & 9.9 & 17.4 & 16.3 & 8.0 & 9.0 \\
$120-129$ & 41.0 & 40.9 & 6.8 & 8.9 & 14.1 & 19.5 & 6.9 & 13.6 \\
Total/Mean & 234.2 & 222.5 & 11.2 & 10.8 & 20.2 & 20.9 & 13.1 & 15.9
\end{tabular}

Source: Shinfield Weather Station, 2000 - 2001, University of Reading,United Kingdom.

\section{Crop measurements}

Plants were sampled during vegetative growth, flowering, tasselling, near physiological maturity and at maturity. At each sampling, plants were harvested from $1 \mathrm{~m}^{-2}$ in each plot by carefully uprooting each plant. This gave six maize plants and 69-71 pea plants per sample. For the intercrops maize and peas were separated into their component crops. All samples were separated into their various above ground components of leaf, stem, flowers, pods, ears and seed and fresh weight was immediately determined. All the six maize plants were used for leaf area determination whilst for peas only eight plants were used. After the leaf area measurement the samples were oven-dried at $81{ }^{\circ} \mathrm{C}$ for $72 \mathrm{~h}$ and their dry weight was measured. Final harvest samples were taken at 85 and 125 DAS for peas and maize, respectively, in 2000 and at 89 and 123 DAS in 2001, for dry weight yield determination. Above ground dry weights were used to calculate the final RUE and CRUE.

\section{Radiation measurements}

Transmission of photosynthetically active radiation (PAR) of the sole and intercrops was measured using a Sunfleck Ceptometer (Delta T Devices), with a sensor length of $80 \mathrm{~cm}$. Measurements were taken

West African Journal of Applied Ecology - Volume 13 
at four positions in each plot at least $1 \mathrm{~m}$ away from the edges of the plot. Before the maize grew above the peas, measurements were taken at the top of the canopy and below. When the canopies were distinct, three measurements were made, above the canopy $\left(\mathrm{I}_{\mathrm{o}}\right)$, above peas $\left(\mathrm{I}_{\mathrm{m}}\right)$, and below the canopy (I), but only the total interception by the intercrops was considered. Measure-ments were normally taken between 10:00-14:00 GMT. Readings were taken weekly, from 36 to 106 DAS in 2000 and from 25 to 127 DAS in 2001 .

The fraction of PAR transmitted $(\mathrm{T})$ was calculated as $\mathrm{I} / \mathrm{I}_{\mathrm{o}}$. The fraction of PAR intercepted $(\mathrm{F})$ is then 1-T. Daily values of the fraction of radiation intercepted was given by linear interpolation between the days of measurements. Daily totals of absorbed PAR that were calculated assumed that daily incoming PAR was 0.5 of daily incoming solar radiation (Monteith, 1972) and that crops reflect 0.1 and, therefore, absorb only 0.9 of the intercepted PAR (Gallagher \& Biscoe, 1977). Daily incoming radiation totals were taken from an automatic weather station (Campbell, Scientific) adjacent to the experimental site, or from a Kipp solarimeter at the University of Reading meteorological station about six $\mathrm{km}$ from the experiments. These two records were virtually identical. Cumulative absorbed PAR was totaled from emergence to maturity.

The radiation use efficiency (RUE) was given by $\left(\mathrm{W}_{2}-\mathrm{W}_{1}\right) /\left(\mathrm{R}_{2}-\mathrm{R}_{1}\right)$ where $\mathrm{W}_{2}$ and $\mathrm{W}_{1}$ were the above ground dry weights and $R_{2}$ and $R_{1}$ the corresponding cumulative absorbed PAR at times $t_{1}$ and $t_{2}$ from sowing. The cumulative radiation use efficiency (CRUE) was calculated as $\mathrm{W} / \mathrm{R}_{t}$. This represents, at any time, the mean RUE over the period from emergence to that time. As it is based on measurements of dry weight at a given time it is subject to less sampling variation than RUE. The final value gives the overall RUE for the life of the crop. On days when leaf area was measured, extinction coefficients were calculated from the relationship $\mathrm{T}=\exp$

$(-\mathrm{kL})$ (Monski \& Saeki, 1953), thus, $\mathrm{k}=-(\ln (\mathrm{T})) / \mathrm{L}$.

\section{Statistical analysis}

Analysis of Variance (SAS, 2000) was used to look for differences in the fraction of PAR intercepted and final dry matter between replicates and treatments. There were significant differences between treatments but not for replicates. Mean separation was done using the least significant difference (LSD) at $5 \%$. No data were transformed prior to statistical analysis. For both variables, therefore, RUE and CRUE were calculated from treatments mean values of dry matter and absorbed PAR.

\section{Fraction of PAR intercepted by entire intercrop}

\section{Results}

In 2000 light interception was greatest in the intercrops, followed by the sole peas with sole maize intercepting the least (Fig. 1a). At 36 DAS the intercrops and the sole peas were intercepting more than 0.5 of the incident irradiance whereas sole maize intercepted less than 0.2. The maximum interception was achieved by 71 DAS for all treatments except sole maize (Fig. 1a). Nancis intercropped with Maro intercepted the most followed closely by Sophy intercropped with Maro. Both sole peas intercepted less radiation compared to their intercropped counterparts, but significantly more than sole maize. However, by the end of the season the sole maize treatments were intercepting comparable amounts of radiation compared to their intercrop counterparts (Fig. 1a). The figure shows that the PAR intercepted by the intercrops, after peas matured, included that intercepted by the pea stubble, which was not removed. 

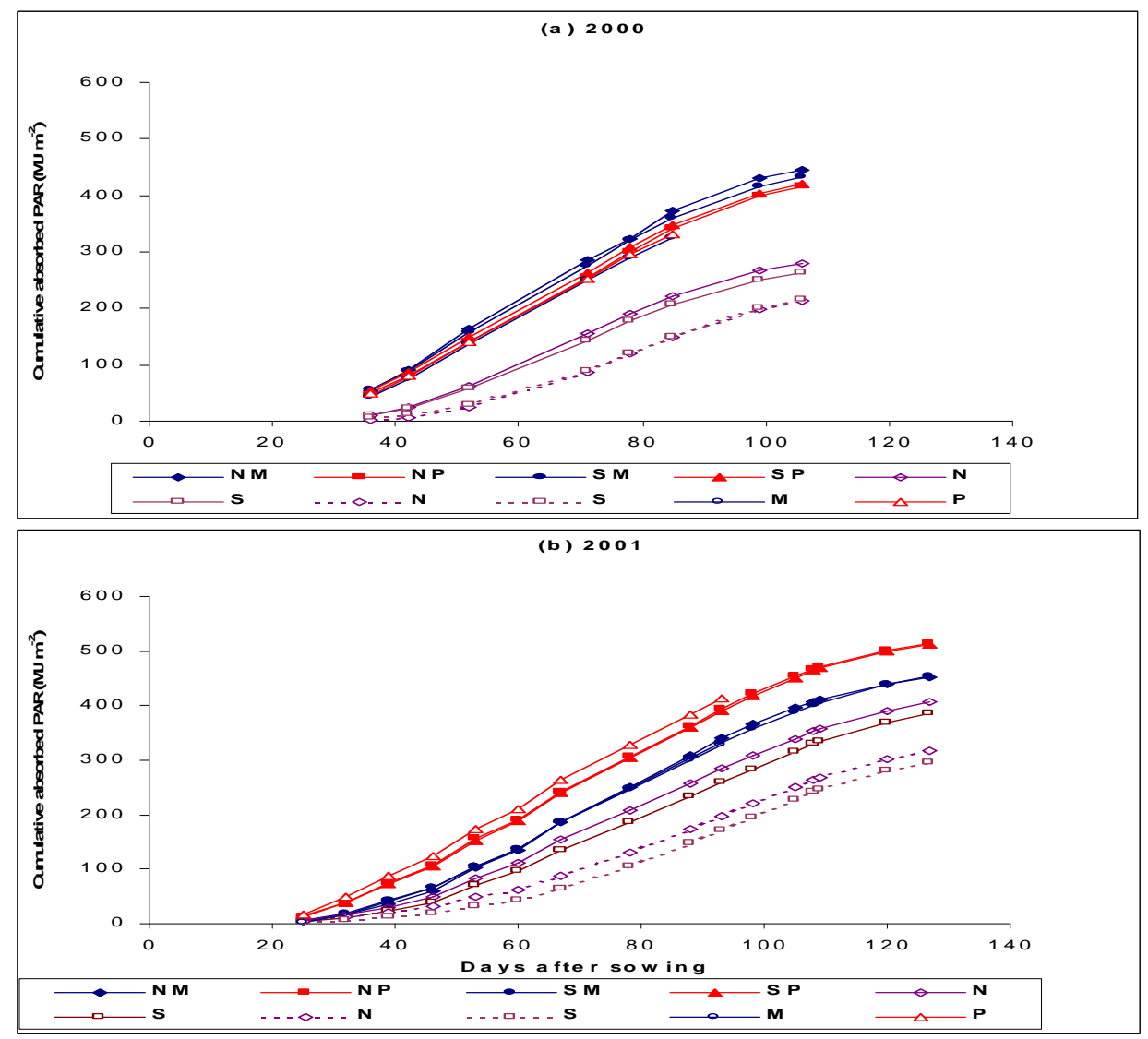

Fig.1. Fraction of PAR intercepted (a) 2000 and (b) 20001 as affected by morphologically contrasting maize-pea cultivars in intercropping and sole cropping. Sole crops of maize are Nancis $(\mathbf{N})$ and Sophy $(\mathbf{S})$. Sole crops of pea are Maro (M) and Princess $(\mathbf{P})$. Intercrops are defined by the initial for maize followed by that for pea. For sole maize the dashed lines show the original values measured and the solid lines the values calculated from extinction coefficients. Bars show LSD at $P=$ 0.05 . 

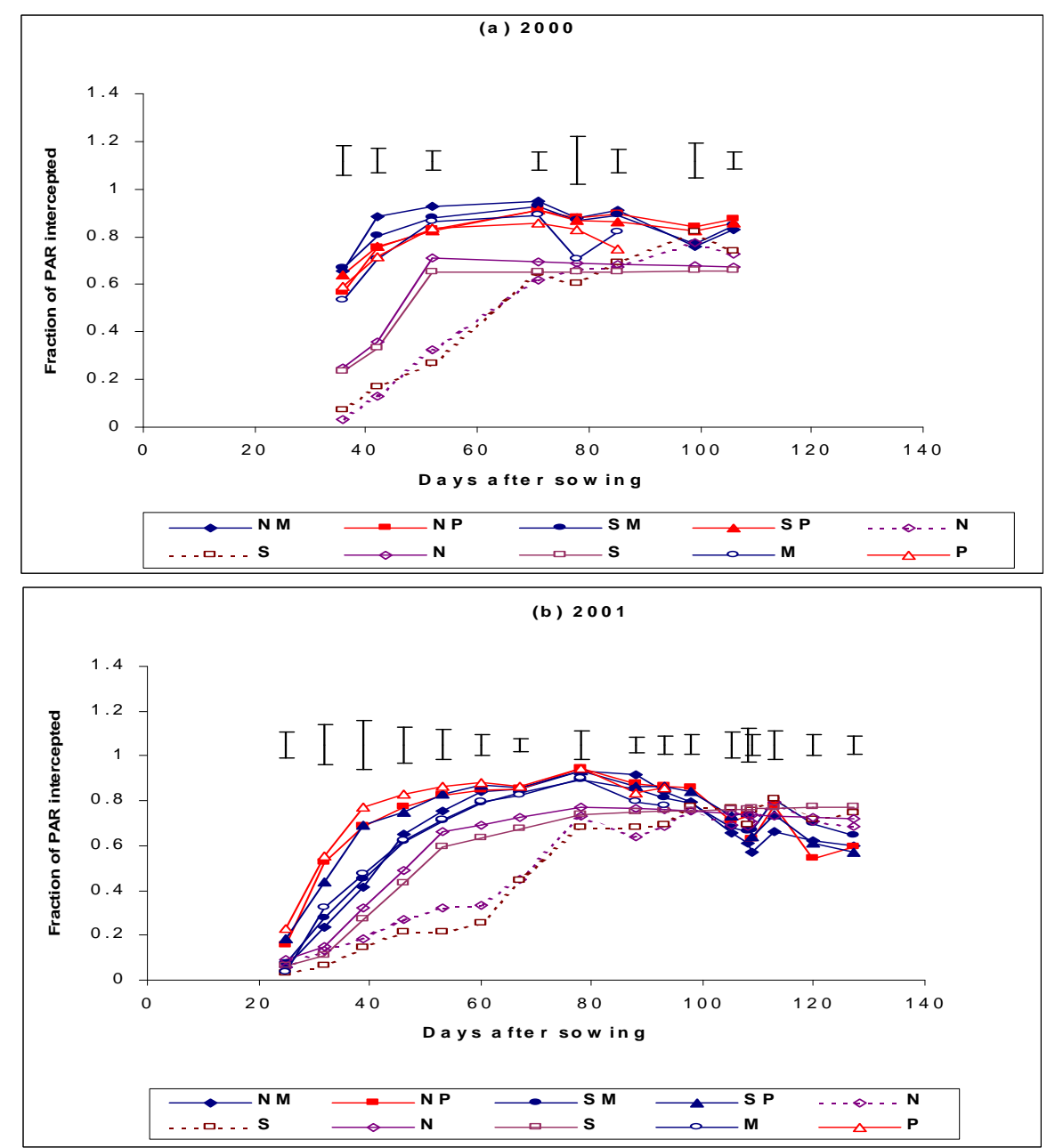

Fig. 2. Cumulative absorbed PAR $\left(\mathrm{MJ} \mathrm{m}^{-2}\right.$ ) (a) 2000 and (b) 20001 as affected by morphologically contrasting maize-pea cultivars in intercropping and sole cropping. Sole crops of maize are Nancis $(\mathbf{N})$ and Sophy $(\mathbf{S})$. Sole crops of pea are Maro (M) and Princess (P). Intercrops are defined by the initial for maize followed by that for pea. For sole maize the dashed lines show the original values measured and the solid lines the values calculated from extinction coefficients.

In 2001 light interception was greatest for Princess in pure stand and for maize intercropped with Princess. Maro sole and intercrops intercepted less with sole maize intercepting the least (Fig. 2b). Princess sole and intercrops were intercepting their maximum radiation of about 0.94 at 71 DAS compared to sole Nancis intercepting only 0.73 and Sophy 0.68. After 99 DAS intercrops and sole maize crops were intercepting similar amounts of radiation. The pattern of radiation interception was similar in both seasons. However, whilst Maro intercropped with maize and in pure stand intercepted the most radiation in the first year, in the second year Princess sole and intercropped intercepted the most radiation. Sole maize in both years consistently intercepted less than 0.5 incoming PAR from beginning to midseason.

The fractions of radiation intercepted were used to calculate daily-absorbed PAR and radiation RUE. The RUE for the intercrops and sole peas seemed reasonable but the RUE for the sole-cropped maize early in the season were unreasonably high, about $10 \mathrm{~g} \mathrm{MJ}^{-1} \mathrm{~m}^{-2}$. Careful examination of the dry weights and radiation data showed no errors. It seems that the interception values were rather low for the sole maize. The experimental technique of measuring the fraction of transmitted radiation is similar to that

West African Journal of Applied Ecology - Volume 13 
employed by other workers, but it may be that this under estimated the radiation intercepted in the sole maize plots grown at a relatively low density, because of the capture of diffuse radiation by isolated plants. A second possible cause was leaf rolling observed in maize at mid-July during a period of drought spell. The dry spell experienced during the 2001 season was also unusual, thus, further compounding the problem encountered in the current study.

Values of extinction coefficients (k) for sole maize are given in Table 2. In both years the values obtained early in the season were erratic and particularly low at 51 and 53 DAS. These days were excluded from analysis. The data from both years were pooled and regression of $-\ln (\mathrm{T})$ on L (leaf area index) for each cultivar gave regressions with intercepts not significantly different from zero (Table 3). Thus, the regressions were forced through the origin for the slope $\mathrm{k}$, giving values of 0.71 for Nancis and 0.66 for Sophy.

TABLE 2

Total above ground dry weight $\left(\mathrm{g} \mathrm{m}^{-2}\right)$ of maize and pea

\begin{tabular}{|c|c|c|c|c|c|c|c|}
\hline & & & & 2000 & & & 2001 \\
\hline Sole pea & Maro & & & 741 & & & 560 \\
\hline & Princess & & & 858 & & & 738 \\
\hline Sole maize & Nancis & & & 1397 & & & 1342 \\
\hline & Sophy & & & 1186 & & & 1134 \\
\hline & & Maize & Pea & Total & Maize & Pea & Total \\
\hline Intercrops & Nancis-Maro & 810 & 921 & 1731 & 946 & 533 & 1479 \\
\hline & Nancis-Princess & 1007 & 621 & 1628 & 855 & 662 & 1517 \\
\hline & Sophy-Maro & 816 & 741 & 1557 & 950 & 481 & 1431 \\
\hline & Sophy-Princess & 927 & 783 & 1710 & 596 & 772 & 1368 \\
\hline & S.E. & 67 & 101 & 111 & 50 & 58 & 69 \\
\hline & Error d.f. & 6 & 6 & 15 & 6 & 6 & \\
\hline
\end{tabular}

TABLE 3

Values of extinction coefficients ( $k$ ), leaf area index (LAI) and fraction of interception by sole cropped Nancis and Sophy

$\begin{array}{cccccccc}\text { Year } & \text { DAS } & \text { LAI }(N) & \text { LAI }(S) & \begin{array}{c}\text { Fraction of } \\ \text { PAR } \\ \text { intercepted } \\ (N)\end{array} & \begin{array}{c}\text { Fraction of } \\ \text { PAR } \\ \text { intercepted } \\ (S)\end{array} & \begin{array}{c}\text { Extinction } \\ \text { coefficient }(k)\end{array} & \begin{array}{c}\text { Extinction } \\ \text { coefficient }(k)\end{array} \\ & & & & & & (N) & (S) \\ 2000 & 28 & 0.07 & 0.08 & 0.02 & 0.05 & 0.30 & 0.62 \\ 2000 & 51 & 1.74 & 1.61 & 0.29 & 0.24 & 0.19 & 0.17 \\ 2000 & 118 & 1.53 & 1.62 & 0.73 & 0.74 & 0.85 & 0.82 \\ 2000 & 126 & 1.54 & 1.6 & 0.73 & 0.74 & 0.84 & 0.83 \\ 2000 & 140 & 1.92 & 1.98 & 0.73 & 0.74 & 0.68 & 0.67 \\ 2001 & 31 & 0.19 & 0.14 & 0.11 & 0.05 & 0.61 & 0.38 \\ 2001 & 53 & 1.52 & 1.37 & 0.31 & 0.22 & 0.25 & 0.18 \\ 2001 & 79 & 2.12 & 2.09 & 0.73 & 0.68 & 0.62 & 0.54 \\ 2001 & 123 & 1.79 & 2.26 & 0.70 & 0.72 & 0.68 & 0.57\end{array}$

The fraction of radiation intercepted by the sole maize was re-calculated using these extinction coefficients and the measured leaf area index shown (Fig.1). In both years these recalculated values increased interception early in the season, but the sole maize still intercepted less radiation than the other treatments ranging from 0.6 to 0.7 by 50 DAS.

Cumulative absorbed PAR

West African Journal of Applied Ecology - Volume 13 
The cumulative PAR absorbed in 2000 is shown (Fig. 2a). The two lowest lines are those for the sole maize using the original measured low fractional interception values, whilst the middle lines are those obtained using the new values of fractional interception recalculated using $\mathrm{k}$ and $\mathrm{L}$. The intercrops and sole pea treatments absorbed significantly more PAR compared to the sole cropped maize. Sole pea absorbed only slightly less than the intercrops. The greatest absorbed PAR by 106 DAS was by NancisMaro (445 $\mathrm{MJ} \mathrm{m}^{-2}$ ) followed by Sophy-Maro (432 $\left.\mathrm{MJ} \mathrm{m}^{-2}\right)$. Sophy-Princess absorbed $420 \mathrm{MJ} \mathrm{m}^{-2}$ and Nancis-Princess $416 \mathrm{MJ} \mathrm{m}^{-2}$. Sole Nancis absorbed slightly more PAR (280 MJ m²) than Sophy (263 MJ $\left.\mathrm{m}^{-2}\right)$.

In 2001, Princess in pure stand absorbed the highest PAR followed by Sophy-Princess and NancisPrincess (Fig. 2b). At the end of the season (123 DAS) the intercrops had absorbed significantly higher PAR compared to their sole cropped counterparts. Mean PAR absorbed at the end of season were NancisPrincess (507 $\mathrm{MJ} \mathrm{m}^{-2}$ ), Sophy-Princess (505 $\mathrm{MJ} \mathrm{m}^{-2}$ ), Sophy-Maro and Nancis-Maro (453 $\mathrm{MJ} \mathrm{m}^{-2}$ ), Nancis (308 $\left.\mathrm{MJ} \mathrm{m}^{-2}\right)$, Sophy (287 $\mathrm{MJ} \mathrm{m}^{-2}$ ). Princess and Maro by harvest at $90 \mathrm{DAS}$ had absorbed $397 \mathrm{MJ} \mathrm{m}^{-2}$ and $314 \mathrm{MJ} \mathrm{m}^{-2}$, respectively.

The absorbed PAR for all treatments was higher in 2001 compared to that obtained in 2000. In 2000, maize intercropped with Maro resulted in higher absorbed PAR compared to the intercrops with Princess or the sole crops. However, in 2001 Princess sole or intercropped consistently absorbed more PAR values than Maro. Nancis in pure stand consistently absorbed more radiation than Sophy.

\section{Final above ground dry matter}

The dry matter obtained in 2001 for the intercrops and sole peas was greater than in 2000 (Table 4). However, for sole maize, the dry matter in 2000 was $8 \%$ greater than in 2001 . The mean final dry matter achieved in 2000 were $1393 \mathrm{~g} \mathrm{~m}^{-2}$ for intercrops, $1317 \mathrm{~g} \mathrm{~m}^{-2}$ for sole maize and $541 \mathrm{~g} \mathrm{~m}^{-2}$ for sole pea, whilst in 2001 the values were $1521 \mathrm{~g} \mathrm{~m}^{-2}$ for the intercrops, $1222 \mathrm{~g} \mathrm{~m}^{-2}$ for sole maize and $649 \mathrm{~g} \mathrm{~m}^{-2}$ for sole pea.

TABLE 4

Regression of -ln T on L for Nancis and Sophy. $k$ is the regression forced through the origin

\begin{tabular}{llrrc} 
Cultivar & \multicolumn{1}{c}{ Slope } & Intercept & $r^{2}$ & \multicolumn{1}{c}{$K$} \\
Nancis & $0.694(0.080)$ & $0.030(0.122)$ & 0.937 & $0.711(0.0371)$ \\
Sophy & $0.626(0.0987)$ & $0.055(0.159)$ & 0.892 & $0.655(0.047)$
\end{tabular}

\section{Radiation use efficiency (RUE)}

In Fig. 3 RUE was plotted against the end day of each period. The intercrops and sole Maro had the highest initial RUEs (2.0-2.2 $\mathrm{g} \mathrm{MJ}^{-1}$ ) in 2000 (Fig. 3a). Sole maize and sole Princess had lower RUEs of 1.8, 1.5 and $1.2 \mathrm{~g} \mathrm{MJ}^{-1}$ for Nancis, Princess and Sophy, respectively. Thereafter, sole maize generally had higher RUE than the intercrops. At 115 DAS the highest RUE were obtained for the sole Nancis $(5.5 \mathrm{~g}$ $\left.\mathrm{MJ}^{-1}\right)$, Nancis-Maro $\left(5.2 \mathrm{~g} \mathrm{MJ}^{-1}\right)$ and sole Sophy $\left(4.8 \mathrm{~g} \mathrm{MJ}^{-1}\right)$. Intercrops with Maro had values of $3.0 \mathrm{~g} \mathrm{MJ}^{-}$ ${ }^{1}$ but those with Princess were lower $\left(2.6 \mathrm{~g} \mathrm{MJ}^{-1}\right)$. Throughout the season, sole peas had the lowest values ranging from $0.9 \mathrm{~g} \mathrm{MJ}^{-1}$ to $2.4 \mathrm{~g} \mathrm{MJ}^{-1}$.

In 2001 the sole maize had initially lower values compared to the intercrops. However, for much of the season the intercrops had comparable RUE with the sole maize. The sole pea had considerably lower values throughout the season $\left(<2.0 \mathrm{~g} \mathrm{MJ}^{-1}\right)$. Sole Nancis had greater RUE than Sophy for much of the season (Fig. 3b). 

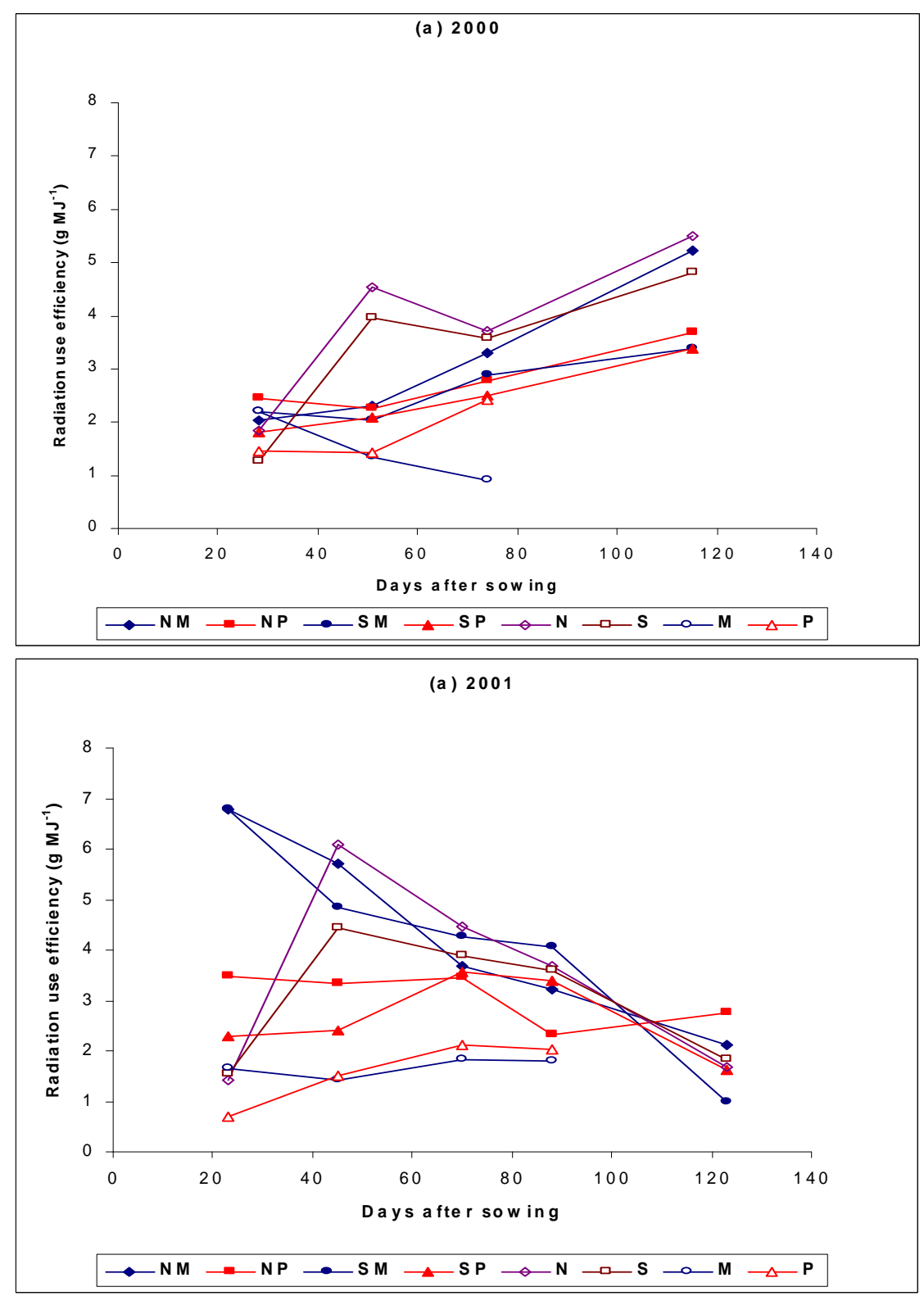

Fig. 3. Radiation use efficiency (g MJ-1) (a) 2000 and (b) 20001 as affected by morphologically contrasting maize-pea cultivars in intercropping and sole cropping. Sole crops of maize are Nancis $(\mathbf{N})$ and Sophy $(\mathbf{S})$. Sole crops of pea are Maro $(\mathbf{M})$ and Princess $(\mathbf{P})$. Intercrops are defined by the initial for maize followed by that for pea.

\section{Cumulative radiation use efficiency (CRUE)}

The first observation of CRUE is the same as the RUE described above. Subsequently, in 2000 sole maize treatments recorded consistently higher CRUE and the sole peas lowest throughout the season (Fig. 4a). At the end of sampling the overall CRUE attained were Nancis $4.6 \mathrm{~g} \mathrm{MJ}^{-1}$, Sophy $4.2 \mathrm{~g} \mathrm{MJ}^{-1}$, NancisMaro 3.7 $\mathrm{g} \mathrm{MJ}^{-1}$, Sophy-Maro $3.9 \mathrm{~g} \mathrm{MJ}^{-1}$, Sophy-Princess $3.8 \mathrm{~g} \mathrm{MJ}^{-1}$, Nancis-Princess $3.6 \mathrm{~g} \mathrm{MJ}^{-1}$, sole Princess 1.9 $\mathrm{g} \mathrm{MJ}^{-1}$ and sole Maro $1.2 \mathrm{~g} \mathrm{MJ}^{-1}$.

West African Journal of Applied Ecology - Volume 13 

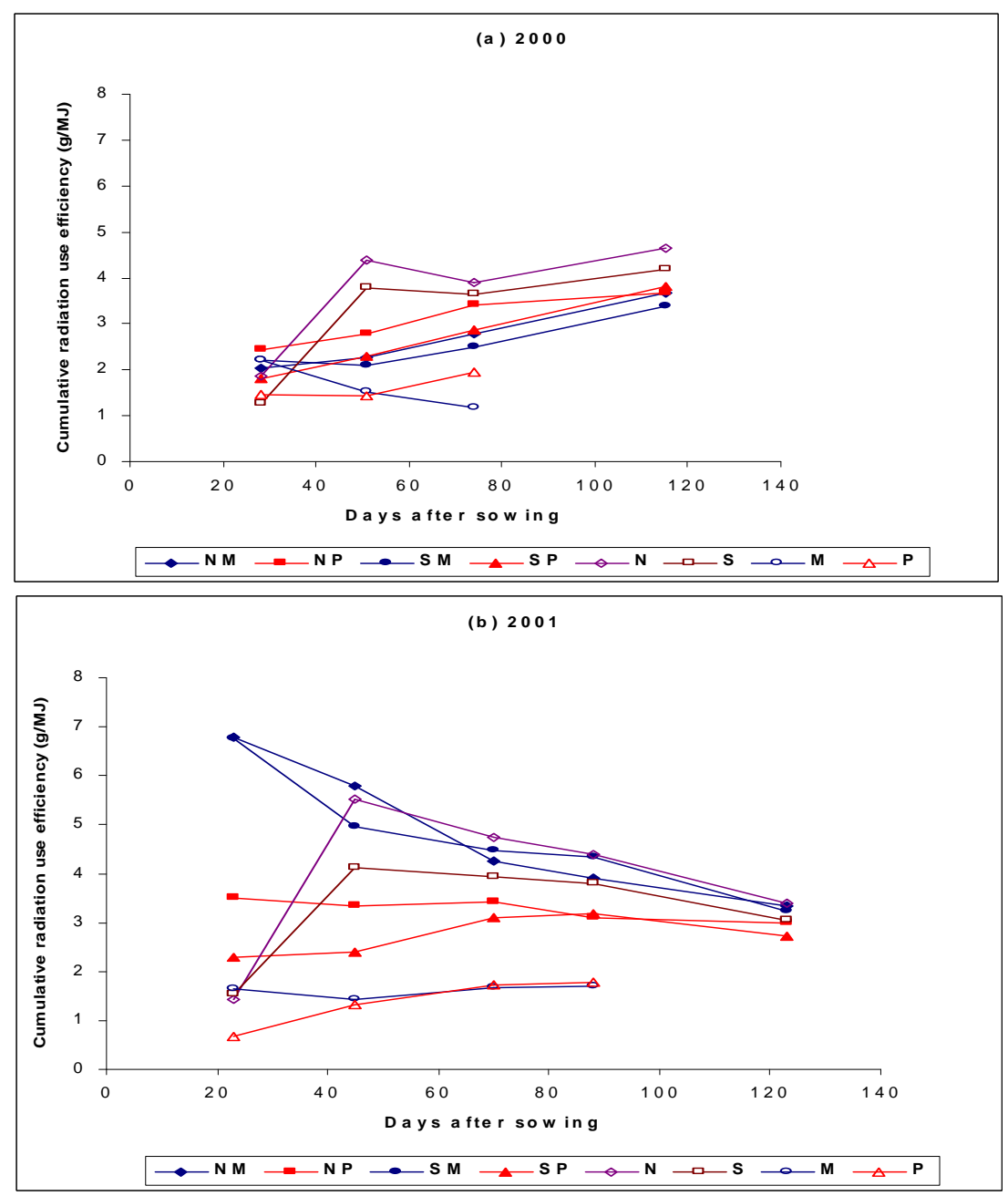

Fig. 4. Cumulative radiation use efficiency ( $\mathrm{g} \mathrm{MJ}^{-1}$ ) (a) 2000 and (b) 20001 as affected by morphologically contrasting maize-pea cultivars in intercropping and sole cropping. Sole crops of maize are Nancis (N) and Sophy (S). Sole crops of pea are Maro (M) and Princess $(\mathbf{P})$. Intercrops are defined by the initial for maize followed by that for pea.

In 2001 intercropping both maize cultivars with Maro resulted in consistently higher CRUE in the early part of the season compared with the other intercrops and the sole maize and pea (Fig. 4b). At the end of the season the final CRUEs were similar for sole maize and intercrops: Nancis $\left(3.4 \mathrm{~g} \mathrm{MJ}^{-1}\right)$, Nancis-Maro (3.3 $\mathrm{g} \mathrm{MJ}^{-1}$ ), Sophy-Maro (3.2 $\mathrm{g} \mathrm{MJ}^{-1}$ ) and Nancis-Princess and Sophy (3.0 $\left.\mathrm{g} \mathrm{MJ}^{-1}\right)$, SophyPrincess $\left(2.7 \mathrm{~g} \mathrm{MJ}^{-1}\right)$. Sole peas again had lower values with Princess $1.8 \mathrm{~g} \mathrm{MJ}^{-1}$ and Maro $1.7 \mathrm{~g} \mathrm{MJ}^{-1}$.

The values of CRUE for sole maize were similar in the 2 years. The intercrops with Maro had greater CRUEs in 2001 than 2000. In 2001 the intercrops had greater initial CRUE than the sole crops but similar with the sole maize for the rest of the season.

\section{Discussion}

Many studies, mostly tropical, have shown that intercrops intercept more PAR than sole crops; Sivakumar \& Virmani (1980) for maize-pigeon pea intercrops, Bandy-opadhyay (1988) for sorghum and mung bean, and Tsubo et al. (2001) for maize bean intercrops. The present study confirmed that the intercrops captured more radiant energy than sole crops, but the differences between the intercrops and the sole pea crops were relatively small and not significant. The superior interception by the intercrops might be

West African Journal of Applied Ecology - Volume 13 
attributed to the complementarity in time and higher plant populations for the intercrops. Pea had a fast initial growth rate compared to maize and covered the soil surface very early resulting in higher interception of photosynthetic active radiation compared to maize. However, after maturity of pea the intercropped maize grew rapidly and was intercepting similar or slightly greater PAR than the sole maize crops.

The concept of CRUE has been used to assess radiation use efficiency for intercrops and sole crops. The CRUE represents, at any time, the mean RUE over the period from emergence to that time. As it is based on measurements of dry weight at one time it is subject to less sampling variation than RUE. The final value is the overall RUE for the life of the crop. This is, therefore, a better and more reliable approach to determining RUE than the ubiquitous regression of dry matter on intercepted PAR or absorbed PAR.

As expected, RUE and CRUE were greater for sole maize than for sole peas. Seasonal values were about $4 \mathrm{~g} \mathrm{MJ}^{-1}$ for maize and between 1 and $2 \mathrm{~g} \mathrm{MJ}^{-1}$ for pea. This is consistent with general difference between $\mathrm{C}_{4}$ and $\mathrm{C}_{3}$ crops. Squire (1993) reported RUE of $4.5 \mathrm{~g} \mathrm{MJ}^{-1}$ PAR for tropical $\mathrm{C}_{4}$ cereals compared to about $2.5 \mathrm{~g} \mathrm{MJ}^{-1}$ for legumes and other $\mathrm{C}_{3}$ crops. Sinclair \& Muchow (1999) concluded that generally $\mathrm{C}_{4}$ species have higher RUE than $\mathrm{C}_{3}$ species because of differences in photosynthetic rates and the energy content of plant products, but there are exceptions. The values measured here for maize are similar to the higher values in the literature (e.g. Kiniry et al., 1989; Daughtry et al., 1992; Tollenaar \& Aguilera, 1992; Andrade et al., 1993). The values for pea are similar to the $1.46 \mathrm{~g} \mathrm{MJ}$ intercepted PAR reported by Heath \& Hebblethwaite (1985).

The initial values for maize were low, possibly because of overestimation of radiation interception but are of little consequence in determining seasonal values. Low temperature after sowing may also be responsible for low RUE in maize (Andrade et al., 1992). In both years, Nancis absorbed slightly more radiation and had slightly greater RUE and CRUE than Sophy (hypothesis a). There were no consistent differences in RUE between the sole pea cultivars. Maro had more leaf area and greater radiation absorption than Princess in 2000 but in 2001 Princess intercepted considerably more radiation than Maro. The differences in performance of the two pea cultivars could be ascribed to the differences in rainfall distribution in 2000 and 2001, and the physiological and morphological differences between the two pea cultivars.

In 2000 the intercrops had RUE and CRUE values intermediate between the high values of sole maize and the lower values of sole pea. The final CRUE values were in the range 2.4-2.9 $\mathrm{g} \mathrm{MJ}^{-1}$. In 2001 the final CRUE for the intercrops were slightly greater, ranging from 2.7 to $3.3 \mathrm{~g} \mathrm{MJ}^{-1}$ and similar to that of sole maize reported by Sivakumar \& Virmani (1984) for maize pigeon pea intercrops.

Resource capture and use differed between the combinations of cultivars (hypothesis d), but also varied between years. The radiation absorbed by the intercrops was dominated by that of the pea component, with Maro capturing more in 2000 and Princess in 2001 (hypothesis d). However, in both years intercrops with Nancis as the maize component had higher CRUE than Sophy, as found for both sole crops. More detailed investigation is required to establish whether these differences resulted from morphological or physiological differences between the cultivars. These findings have significant implications, particularly for farmers in the savanna agroecology where intercropping of cereals with legumes are the dominant cropping systems, and where resource capture and use are critical. Most farmers in these ecologies usually use their local landraces in the intercrops as most of the improved varieties, particularly cowpeas, perform rather poorly in the intercrops. Optimal crop characteristics of the cereal and legume crops are, therefore, very important for optimum and stable yields.

In this study the erect leaved maize cultivar and the semi-leafless pea were most compatible as they intercepted and used photosynthetic radiation most efficient compared to the droopy leaved maize and the normal leaved pea. This cropping combination also performed best in years of adequate rainfall distribution and in years where the rainfall distribution was erratic. This kind of rainfall distribution is

West African Journal of Applied Ecology - Volume 13 
typical of the arid and semi-arid savanna agroecologies of the tropics. Therefore, farmers in these agroecologies will have to select intercrop partners bearing in mind the compatibility of the crops morphology and physiology, if yields are to be optimized and maintained in component crops.

\section{Conclusion}

The results of the study emphasize that radiation capture and efficiency of use in sole and intercrops are greatly affected by morphological characteristics of the component crops. The intercrops and sole peas had relatively similar radiation interception from the beginning to mid-season. The sole maize crops intercepted the least radiation until mid-season but later intercepted amounts similar to the intercrops. Nancis in both intercrops and sole crops absorbed more PAR than Sophy. Due to the variable nature of radiation use efficiency, as been mentioned earlier on in the introduc-tion, the cumulative radiation use efficiency was found to provides a reliable and stable measure of radiation use efficiency.

The sole peas had consistently lower radiation and cumulative radiation use efficiencies compared with the intercrops and sole maize. In 2000 the sole maize had a higher cumulative radiation use than the intercrops and sole peas. In 2001 the intercrops and sole maize had similar cumulative radiation use efficiencies, suggesting an increase in the radiation use efficiency of pea within the intercrops. In selecting intercrop partners the morpholo-gical and physiological compatibility of the component crops should be of paramount importance.

\section{Acknowledgement}

The research was undertaken by R. A. L. Kanton within a PhD Studentship sponsored by The Association of Commonwealth Universities (UK). The authors will like to thank Geoff Ruffles and David McClay for assistance in land preparation.

\section{References}

Andrade F. H., Uhart S. A., Arguissain G. G. and Ruiz R. A. (1992). Radiation use efficiency of maize grown in a cool area. Fld Crops Res. 28: 345-354.

Andrade F. H., Uhart S. A. and Cirilo A. (1993). Temperature affects radiation use efficiency in maize. Fld Crops Res. 32: 1725.

Angus J. F., Jones R. and Wilson J. H. (1972). A comparison of barley cultivars with different leaf inclinations. Aust. J. agric. Res. 23: 945-957.

Anon. (1999a). Recommended varieties of forage maize 1999, National Institute of Agricultural Botany. Cambridge, UK. pp. $295-296$.

Anon. (1999b). Recommended pulse variety handbook 1999. National Institute of Agricultural Botany. Cambridge, UK.

Azam-Ali S. N. and Squire G. R. (2002). Principles of Tropical Agronomy. CABI Publishing, Wallingford, UK. 116 pp.

Bandyopadhyay S. K. (1988). Solar radiation interception, soil water and nitrogen use in sorghum based intercropping system with legumes. Indian J. Agron. 33: 31-36.

Caldwell M. M. (1987). Plant architecture and resource competition. In Ecological Studies. (E. Schulze and H. Zwolfer, ed.), pp. 164-179. Springer-Verlag.

Cudney D. W., Jordan L. S. and Hall H. E. (1991). Effect of wild oat (Avena fatua) infestation on light and growth rate of wheat. Weed Sci. 39: 175-179.

Daughtry C. S. T., Gallo K. P., Goward S. N., Prince S. D. and Kustas W. P. (1992). Spectral estimates of absorbed radiation and phytomass production in corn and soybean canopies. Rem. Sen. Envir. 39: 141-152.

Gallagher J. N. and Biscoe P. V. (1978). Radiation absorption, growth and yield of cereals. J. agric. Sci. 91: 47-60.

Jarvis R. A. (1968) Soils of Reading district. Rothamsted Experimental Station, Harpenden, United Kingdom.

Heath M. C. and Hebblewaite P. D. (1985) Solar radiation interception by leafless, semi-leafless and leafed peas (Pisum sativum L.) under contrasting field conditions. J. appl. Biol. 107: 309-318.

Keating B. A. and Carberry P. S. (993) Resource capture and use in intercropping: solar radiation. Fld Crops Res. 34: $273-301$.

Kiniry J. R., Jones C. A. and O'Toole J. C. (1989). Radiation use efficiency in in biomass accumulation prior to grain filling for five grain-crop species. Fld Crops Res. 20: 51-64.

Monsiki M. and Saeki T. (1953). The light factor in plant communities and its significance for dry matter production. Jap. J. Bot. 14: 22-52.

Monteith J. L. (1972). Solar radiation and productivity of the tropical ecosystems. J. appl. Ecol. 9: 747-766.

Pandey R. K., Saxena M. C., Agrawal B. D. and Subramaniam K. K. (1976). Photosynthetically active radiation in and out of maize canopy in subtropical conditions of Pantnagar. Pantnagar J. Res. 1: 45-47.

West African Journal of Applied Ecology - Volume 13 
Pyke K. A. and Hedley C. L. (1985). Growth and photosynthesis of different pea phenotypes. In The pea crop: a basis for improvement. (P. D. Hebblewaite, M. C. Heath and T. C. K. Dawkins, ed.), pp. 297-305. Butterworth, London.

SAS (2000). Statistical Analysis System Version 8. SAS Institute Inc., Cary NC, USA.

Sinclair T. R. (1972). An evaluation of leaf angle effect on maize photosynthesis and productivity. Dis. Abst. Int. B. 32(1, 12) : $67-68$.

Sinclair T. R. and Muchow R. C. (1999). Radiation use efficiency. Adv. Agron. 65: 215-265.

Sinoquet H. and Caldwell R. M. (1995). Estimation of light capture and partitioning in intercropping systems. In Ecophysiology of Tropical Intercropping. (H Sinoquet and Cruz., ed.), pp. 79-96. INRA, Paris.

Sivakumar M. V. K. and Virmani S. M. (1980). Growth and resource use of maize/pigeonpea intercrop in an operational research watershed. Exp. Agric. 16: 377-386.

Sivakumar M. V. K. and Virmani S. M. (1984). Crop productivity in relation to interception of photosynthetically active radiation. Agric. For. Met. 31:131-141.

Squire G. R. (1993). The Physiology of Tropical Crop Production. CABI Publishing. Wallingford, UK. 236 pp.

Tollenaar M. and Anguilera A. (1992). Radiation use efficiency of an old and a new maize hybrid. Agron. J. 84: 536-541.

Tsubo M., Walker S. and Mukhala E. (2001). Comparison of radiation use efficiency of mono-/inter-cropping systems with different row orientations. Fld Crops Res. 71: 17-29.

Vidovic J. (1979). The effect of changes in leaf angle and LAI on the radiation regime of the stand and on photosynthesis in maize leaves. Rostlinna Vyroba 25: 1247-1256.

Wang Q., Yuzhen N., Qingzhang X., ZhongXiao W. and Jung Z. (1996). Effect of plant- type on rate of canopy apparent photosynthesis and yield in maize. Acta agron. Sin. 22: 223-227.

Willey R. W. (1990). Resource use in intercropping. Agric. Wat. Mgmt 17: 215-231. 